\title{
CHARGED PARTICLES
}

\section{BOOK REVIEWS}

\section{MEN WITH THEIR K'S \\ Memoirs of a New Man}

By William Cooper. Pp. viii +277 . (London : Macmillan and Co., Ltd., 1966.) 25s. net.

THE heroes of the novels of the scientific administrator who writes under the name of William Cooper have now got to the top. No longer provincial schoolmasters or ambitious red-brick scientists, they have now all got their K's. Whereas The Struggle of Albert Woods showed the author as a scientific John Braine, except that he seemed anxious to demonstrate that scientists fight their way to the top in a more urbane fashion than arts men, his latest book is concerned with the intrigues that take place in Oxbridge colleges and the corridors of power. But again the author's irony and humanity civilize the struggles he portrays.

The narrator is a metallurgist, a professor and Fellow of Clarendon College, Oxford - a mirror image of a recent foundation elsewhere. He is also a part-time member of the National Power Board, a vast amalgam of tho A.E.A. and the nationalized fuel and power industries. In its London headquarters, and in its research stations, the intrigues among the members of the Board are the outcome of the rivalry between scientists, engineers, and artstrained administrators. The chairman is an ex-Civil Servant, extremely tall, brilliant, and quite ruthless, but with a contempt for the scientists and engincers that precludes attempts at simple identification.

At Oxford the intrigue is about the appointment of a reearch fellow, and about the part that non-scientific fellows should play in a college primarily founded to support science and technology. It is slightly complicated by a love affair between the successful candidate and the narrator's daughter. The latter's ambivalent attitude towards this affair and his understanding relationship with his daughter are portrayed with the author's characteristic charm, and so are the scenes of his family life with the usual aristocratic-born wife. Somehow even a description of the middle-aged couple, slightly drunk after a party, experimenting with one of the more difficult positions of the Kama Sutra, neither offends nor invokes any psycho-analytic speculation.

Unfortunately men at the top are not as interesting as men on the way up. The dynamism of the author's previous novels is lacking, and, although the conflicts of the new men and their methods of resolving them will amuse the "in group" of those who would have had the chance to participate in or observe such conflicts in real life, this novel will not be likely to have a wide appeal. It is well written, as all the author's novels are, but the story develops slowly and the characters, recognizable as types though they are, except for the narrator hardly come to life. The introduction at the end of a coronary as a deus ex machina to solve the Power Board's conflicts of personal power leaves unsatisfied the interest that has slowly been built up.

This is not so good a novel as William Cooper's previous novels and it is difficult to see where his hero can go from the top. But those who enjoy his writing and are fascinated by the subjects with which he deals will nevertheless eagerly await the next one.
Austen Albu
The Special Theory of Relativity

By J. Aharoni. Second edition. Pp. $x+331$. (Oxford: Clarendon Press; London: Oxford University Press, 1965.) 70s. net.

THIS is the second edition of a book which was first published as recently as 1959 . The new edition contains a much expanded treatment of relativistic charged particle electrodynamics, but is otherwise unchanged.

Aharoni's avowed aim is to make available to students with modest mathematical background the entire mathematical machinery which has grown up around the special theory of relativity and the Lorentz transformation. He has in mind the calculus of tensors, including the spinor calculus, and throws in some group theoretical aspects for good measure. In addition, he covers the formal aspects of the classical theory of fields, scalar and vector, together with the variational principle in its most general form, that is, allowing for the variation of the boundaries and the conservation laws which follow. Here and there, one finds allusion to quantum concepts; so in particular in the last, big chapter on spinors where such concepts as "Hilbert space" and "observable" are quite casually introduced.

The dust cover flap states that "as regards the physical content, it is assumed that the reader is already acquainted to some extent with classical dynamics, Maxwell's theory, and elementary quantum theory". One is tempted to add "knowledge of the physical content of the special relativity theory is also assumed". To be sure, there is an introductory chapter on space and time in inertial systems, in which the formalism of the Lorentz transformation and the standard implications is set up in some painstaking detail, but even here the emphasis is on formal aspects: discussion of the Michelson experiment, the Doppler effect, etc., is relegated to an appendix in small print. From there on, everything is formal and mathematical. The pace is quite leisurely and all calculations are certainly performed in very great detail. First we have the tensor representations of the three-dimensional rotation group, the covariant version of Maxwell's theory, and this is followed by a chapter on general field theory. Next is a chapter on relativistic particle dynamics which lays emphasis on electron theory, radiation reaction, and the Dirac model, and covers somewhat sketchily the Feynmann-Wheeler absorber model for radiative reaction. Rohrlich's recent contributions to the old self-energy and stability problem for the point electron are quite adequately covered, but it seems odd that the truly covariant criterion for radiation is missed out. I found this much the best part of the book.

There is a brief chapter on relativistic hydrodynamics and then a long chapter on spinors. The relationship of the unimodular group to the Lorentz group is spelled out without previous careful elucidation of its relationship to the rotation group in three dimensions. This is worked in piecemeal. The discussion of ray representations is rather unsatisfactory and the "infinitesimal" developments are sketchy. Still, the technique of the relativistic spinor calculus ("dotted and undotted" spinors) deserves wider dissemination, and this book covers the ground in its formal aspects. Many readers perhaps may still ask "What is it all about?"

There will probably be students who will find this book very helpful, and for others it may act as a curtain raiser. I find myself at variance with the author's declared sentiment that painstaking attention to the calculational aspects of the formalism ipso facto paves the way to an understanding of physical theory.

Layout and printing are as one has come to expect of the Clarendon Press.

S. ZIENAU 